\title{
Possibilidades e (in)viabilidades do espanhol na educação básica: as leis da metade
}

Fernanda Peçanha Carvalho

Recebido em: 21 de maio de 2019

Aceito em: 18 de agosto de 2019
Doutora em Linguística Aplicada pela Universidade Federal de Minas Gerais. Atualmente é professora de língua espanhola do Colégio Técnico da UFMG. Contato: nandafale@yahoo. com.br Brasil 


\author{
PALAVRAS-CHAVE: \\ Língua espanhola; \\ Políticas linguísticas; \\ Acontecimento discursivo; \\ Lei 13.415/2017; Análise \\ do Discurso.
}

Resumo: Problematizamos neste artigo dois conjuntos de discursividades: os sistemas de enunciabilidade tanto da possibilidade quanto da (in) viabilidade do ensino-aprendizado de espanhol. Nosso corpus está constituído pela textualidade da Lei n 11.161/2005, Resolução n² 2.742/2015, Lei n 13.415/2017 e por dizeres de professores de espanhol. Sob o paradigma discursivo-psicanalítico, a partir do viés interpretativista, acionamos a vertente francesa da Análise do Discurso com atravessamento da psicanálise e em diálogo com as Ciências Sociais (Pêcheux, 2008; Foucault, 2003, 2013). Desse modo, depreendemos os efeitos de sentido das discursividades das leis e as representações dos dizeres dos sujeitos-professores acerca desses dispositivos. Concluímos que a enunciabilidade da possibilidade ressignificou os conflitos decorrentes do processo de textualização da Lei do Espanhol. E que os dizeres da (in)viabilidade agravam assimetrias, reproduzem e legitimam desigualdades sociais, reduzindo as perspectivas de uma educação linguística plural nas escolas brasileiras.

Abstract: In this article, we discuss two sets of discourses: the system of enunciability of the possibility and the system of enunciability of the (in) viability of Spanish teaching and learning. Our corpus is established by the textuality of Law 11.161/2005, Resolution 2.742/2015, Law 13.415/2017, and reports of Spanish teachers. Based on the discursive-psychoanalytic paradigm, from an interpretative perspective, we count on the theoretical contribution of French Discourse Analysis with the intersection of psychoanalysis and in connection with Social Sciences (Pêcheux, 2008; Foucault, 2003, 2013). Therefore, we examine the meaning effects of the laws and the representations in teachers' reports about these devices. Our analysis allowed us to conclude that the enunciability of possibility re-signified the conflicts arising from the textualization process of the Spanish Law. Also, the words of (in)viability worsen asymmetries, reproduce and lesitimize social inequalities, thus reducing the perspectives of pluralistic language education in Brazilian schools. 


\section{COMO RESISTIR E SEGUIR ENSINANdO ESPANHOL COMO LíNGUA ESTRANGEIRA (E/LE) NA EDUCAÇÃO BÁSICA BRASILEIRA?}

Objetivamos neste artigo possibilitar aos professores de espanhol como língua estrangeira (E/LE), especialmente aos do ensino básico, uma reflexão sobre as condiçóes de produção dos discursos das políticas linguísticas atuais e seus efeitos de sentido na prática de ensino nas salas de aula. $\mathrm{O}$ fazemos através da Linguística Aplicada, em interface com as Ciências Sociais, acionando os conceitos de globalização (Canclini, 2003; Souza Santos, 2011) e desigualdades escolares (Bourdieu, 1979). Também recorremos à Análise do Discurso (AD) de vertente francesa e aos conceitos de acontecimento discursivo (Pêcheux, 2008, 2010) e arquivo (Foucault, 2003, 2013) para a análise do sistema de enunciabilidade da possibilidade e do sistema de enunciabilidade da (in)viabilidade do ensino-aprendizado de espanhol, que formam o arquivo jurídico das políticas linguísticas brasileiras.

Tomando a noção de acontecimento (Pêcheux, 2008) como um enunciado que cria uma ruptura com enunciados anteriores, dando origem a outros, há reverberações de sentido da Lei no 11.161/2005 e resistências à medida provisória no $746^{1}$, promulgada na Lei no $13.415 / 2017$, que geraram acontecimentos singulares (Carvalho, 2015). Esses acontecimentos nomeamos como sistema de enunciabilidade das possibilidades do ensino-aprendizado do espanhol, que confere efeitos de sentido mais positivos ao discurso das legislaçóes no que tange ao E/LE.

1 Informaçôes oficiais sobre a MP no 746, disponíveis em: <https://www.congressonacional.leg.br/ materias/medidas-provisorias/-/mpv/126992>. Acesso em: 26/03/2019. 
Os principais acontecimentos do arquivo jurídico do sistema de enunciabilidade da possibilidade do ensino-aprendizado do espanhol ainda estáo reverberando, e outros em andamento. São eles: (1) Em 07 de março de 2019 a notícia Oferta de Lingua Espanhola nas escolas estaduais será mantida ${ }^{2}$ destaca o trabalho do Movimento Fica Espanhol Sergipe e a permanência da oferta da disciplina Língua Espanhola nas escolas da rede estadual de ensino; (2) Em 05 de novembro de 2018, a matéria intitulada Lei prevê língua espanhola no ensino fundamental das escolas estaduais da $P B^{3}$ apresenta a publicaçáo da Lei no 11.191 no Diário Oficial do Estado (DOE) da Paraíba, que prevê a oferta da disciplina de Língua Espanhola na grade curricular da rede estadual de ensino. Tal disciplina passa a ser facultativa nas escolas públicas estaduais de ensino fundamental; (3) Em Rondônia é publicada a Lei $\mathrm{N}^{\circ}$ 4.394, em 3 de outubro de 2018, que em seu artigo 10 determina: "A oferta da disciplina de Lingua Espanhola fica introduzida obrigatoriamente no currículo do ensino médio da rede estadual de ensino do Estado de Rondônia, ao lado da Lingua Inglesa".

O deputado Anderson Pereira, autor da Lei, evidencia: "O projeto foi uma resposta à preocupaçáo apresentada pela Associaçáo de Professores de Espanhol do Estado de Rondônia (Apero) que repudiou a atitude do governo federal, que revogou a Lei $\mathrm{n}^{\circ} 11.161$ de 2005, a qual tornava o ensino do

2 A notícia completa pode ser lida em: <https://www.seed.se.gov.br/noticia.asp? cdnoticia=14169>. Acesso em 25/03/2019.

3 A matéria pode ser lida na íntegra em: <https://g1.globo.com/pb/paraiba/noticia/2018/09/05/ lei-preve-lingua-espanhola-no-ensino-fundamental-das-escolas-estaduais-da-pb.ghtml>. Acesso em 26/03/2019. 
Espanhol obrigatório", conforme matéria publicada no site da Assembleia Legislativa do Estado de Rondônia ${ }^{4}$; (4) No Rio Grande do Sul a tramitação da Proposta de Emenda à Constituição no 270/20185 proposta em 16 de agosto de 2018 e promulgada em 19/12/2018, objetiva que o ensino da Língua Espanhola, de matrícula facultativa, constituirá disciplina obrigatória das escolas públicas de ensino fundamental e médio; (5) Em 26 de junho de 2018, no estado de São Paulo, iniciou-se a tramitação do Projeto de Lei no 446 de $2018^{6}$, que torna obrigatório o ensino, ao lado da Língua Inglesa, da disciplina de Língua Espanhola no currículo do ensino médio da rede estadual de ensino.

Esses acontecimentos ressignificaram, pelo discurso político-pedagógico, os conflitos do processo de textualização do acontecimento discursivo singular da Lei no 11.161/2005 e seus desdobramentos negativos na oferta do ensino do espanhol como língua estrangeira. Mobilizando a historicidade, tencionando as discursividades, problematizando os sentidos das políticas linguísticas equivocadas e exercendo uma militância coesa e articulada com os propósitos educacionais de integração regional e pluralidade linguísticocultural, devemos enfrentar o projeto de ignorantização e de desigualdades escolares, iniciada no fim do governo anterior, que vigorou entre 2016 e

4 Texto disponível em: <http://www.al.ro.leg.br/institucional/noticias/lingua-espanhola-sera-obrigatoriano-ensino-medio-a-partir-de-2019-em-rondonia >. Acesso em 26/03/2019.

5 Disponível em: <http://www.al.rs.gov.br/legislativo/ExibeProposicao/tabid/325/SiglaTipo/PEC/ NroProposicao/270/AnoProposicao/2018/Default.aspx?Dod=11/09/2018>. Acesso em 24/03/2019.

6 Processo disponível em: <https://www.al.sp.gov.br/propositural?id=1000211658>. Acesso em 26/03/2019. 
2018, e que insurge com veemência na discursividade do atual governo, iniciado em 2019.

Conforme anunciado anteriormente, nos ancoramos na Linguística Aplicada Contemporânea, entendida como área híbrida, mestiça ou área de indisciplina, como afirma Moita Lopes (2006). Também dialogamos com as Ciências Sociais e, a partir do paradigma discursivo-psicanalítico, pautado na vertente francesa da AD de Michel Pêcheux (2008, 2010), assumimos um aporte teórico-metodológico que problematiza e reflete sobre o sujeito e o funcionamento do discurso em suas condiçóes de produçấo e se interessa pelo modo de produção dos sentidos e suas derivas. Dessa forma, acionamos uma "teoria do discurso vista como lugar de constituição de um sentido que escapa à sua intencionalidade" (Bertoldo, 2011, 341). Teoria esta que prevê a identidade como fragmentária e o sujeito clivado pelo inconsciente, conforme o trabalho de Pêcheux (2008, 2010). Nossa abordagem metodológica qualitativa-interpretativista implica que a concepção de que o fazer ciência está constitutivamente permeada por uma prática discursiva interpretativa, marcada pela subjetividade, pela ideologia, pelo contexto histórico-social e pela manutençáo de um poder constituído.

A seguir, apresentaremos uma análise de algumas legislaçôes que (in) visibilizam o ensino-aprendizado da Língua Espanhola, e, na sequência, abordaremos o discurso de professores de E/LE acerca da legislação. 


\section{2. (IN)VISIBILIZANDO O ENSINO: LeI DO ESPANHOL (2005), RESOLUÇÃO N ${ }^{\circ} 2.742$ (2015)} E A LEI 13.415(2017)

Sob o prisma discursivo, analisamos a Lei do Espanhol, a Resolução No $2.742 / 2015^{7}$ e a Lei $13.415^{8}$, que incorpora a Reformulação do Ensino Médio. Denominamos esse arquivo (Foucault, 2003, 2013), conjunto de determinaçôes preestabelecidas sobre o que pode e deve ser dito, como sistema de enunciabilidade aplicável à (in)viabilidade do ensino-aprendizado do espanhol. Os mencionados documentos são o registro de um não projeto de educação linguística que perpassa a legislação brasileira e, consequentemente, perpassa também minha trajetória como professora em formação em uma universidade pública, como docente de uma escola pública federal e também como pesquisadora. No ano de 2005, quando da promulgação da Lei 11.1619 , eu estava em fase de conclusão da minha Licenciatura em Língua Espanhola. Entendida como uma política linguística importante para a integração regional latino-americana, a legislação sobre o ensino-aprendizagem de Língua Espanhola gerou, à época, uma boa expectativa com relação ao mercado de trabalho para todos os graduandos da área.

7 O documento pode ser acessado em: <http://jornal.iof.mg.gov.br/xmlui/handle/123456789/137325? paginaCorrente $=01 \&$ posicaoPagCorrente $=137317 \&$ linkBase $=$ http $\% 3 \mathrm{~A} \% 2 \mathrm{~F} \% 2 \mathrm{Fjornal}$.iof.mg.gov . br\%3A80\%2Fxmlui $\% 2$ Fhandle $\% 2 F 123456789 \% 2 F \&$ totalPaginas=60\&paginaDestino=9\&indice $=0>$. Acesso em 21/05/2019.

8 A íntegra da legislação pode ser acessada em: <http://www.planalto.gov.br/ccivil_03/_Ato20152018/2017/ Lei/L13415.htm\#art22>. Acesso em 27/03/2019.

9 O texto integral da lei pode ser lido em <http://www.planalto.gov.br/ccivil_03/_Ato20042006/2005/ Lei/L11161.htm >. Acesso em 27/03/2019. 


\section{LeI DO ESPANHOL: EFETOS DA LeI DAS METAdeS}

No ano de 2005, em um contexto político-econômico neoliberal e de forte tendência populista, a Lei 11.161 foi elaborada e sancionada. Portanto, possíveis motivaçôes para sua promulgação referem-se à localização geopolítica do Brasil em meio à América hispanofalante; ao fortalecimento do bloco econômico MERCOSUL e ao processo de crescimento econômico brasileiro em meio a um cenário de crise mundial (cf. Carvalho, 2017). As condiçóes de produção da referida Lei ancoram-se na política econômica neoliberal, de ideologia capitalista, que concebe a educação de acordo com a lógica de mercado, logo, devendo funcionar à sua semelhança.

Após um processo histórico de ampliação da disciplina, chegamos ao ano de 2005 com a promulgaçáo da Lei 11.161, concebida por Carvalho (2015) como acontecimento discursivo singular de um arquivo. Com o intuito de fortalecer e ampliar relaçóes econômicas, comerciais e culturais com a América Latina, apresentou-se uma política linguística que, via legislação, define qual idioma deve ser ofertado. Portanto, tínhamos uma relação de verdade estabelecida: a de aprender espanhol por meio de uma oferta obrigatória como importante estratégia para a solidificação de uma soberania política e econômica brasileira na América Hispânica.

Nesse âmbito, remetemos a Pêcheux (2008), e à sua elaboração de que é preciso olhar o discurso como estrutura, mas também como acontecimento e pensar no equívoco da língua, já que o real da língua tem um furo. No que tange à discursividade do enunciado da Lei 11.161, buscamos pontos de deriva possíveis porque, uma vez sujeito ao equívoco, um enunciado pode 
sempre derivar para outro. E são os esquecimentos (Pêcheux, 2010) que permitem essas derivas de sentido.

A materialidade linguística do artigo $1^{\circ}$ da Lei 11.161, determina que "o ensino da língua espanhola, de oferta obrigatória pela escola e de matrícula facultativa para o aluno, será implantado, gradativamente, nos currículos plenos do ensino médio" (Brasil, 2005, grifos nossos). Para tanto, lembramos que Pêcheux (2008) atesta que o sujeito experimenta duas formas de esquecimento: N. 1: ele se esquece de que não é origem do dizer, e N. 2: ele se esquece de que esse dizer poderia ser entendido de outra maneira. Nesse enunciado, o esquecimento $n^{\circ} 2$ (cf. Pêcheux, 2008) dá ao sujeito a ilusão de que tudo o que diz tem apenas um significado. Conforme Eckert-Hoff (2002), portanto, o sujeito se esquece de que são os outros do discurso que determinam esse dizer. $\mathrm{O}$ sujeito, assim, não tem controle dos efeitos de sentido causados por seu dizer. No caso dessa legislação, por exemplo, o que seria oferta obrigatória, currículo pleno e matrícula facultativa? Por mais que se registrem com detalhes esses termos na legislação, a linguagem é opaca e a compreensão dessa lei, em cada cidade do país, não pode ser controlada.

$\mathrm{O}$ acontecimento se refere a um discurso que rompe com a estrutura vigente e instaura outros sentidos a partir dele (Pêcheux, 2008). Nesse sentido é que compreendemos a Lei 11.161, retomando, respectivamente, as noçóes de Pêcheux e de Foucault, como acontecimento discursivo singular de um arquivo. Essa é a segunda legislação que possibilita que o espanhol apareça como disciplina de oferta obrigatória e a primeira lei a apresentar exclusivamente a língua espanhola como foco da legislação, "ponto de 
encontro de uma atualidade e uma memória" (Pêcheux, 2008, 17), que faz eco e que remete a um conteúdo sócio-político da história da política linguística brasileira.

Assim sendo, a noçáo de arquivo - os sistemas de enunciados (acontecimentos e coisas), ou a lei do que pode ser dito, o sistema que rege o aparecimento dos enunciados como acontecimentos singulares, de acordo com Foucault (2013) nos permite considerar os discursos como acontecimentos. O arquivo remete aos discursos pronunciados numa dada época e que continuam a existir através da história. Nesse sentido, a Lei no 11.161/2005, como acontecimento discursivo singular de um arquivo, traz em sua materialidade discursiva, em suas regras e em seu funcionamento, o objetivo de assegurar, nas práticas, a constituiçáo de um poder. Este acontecimento, transformado ao longo da história, possibilitou o surgimento de outros discursos que produziram uma explosão de sentidos.

Nos elementos linguísticos da legislação, a presença de sintagmas que indicam o caráter injuntivo da lei, como: "deverá", "será", "implementarão", "emitirāo", "estimulará", "apoiará", expressos por verbos no futuro, apontam para a perspectiva de efetiva implementaçáo da lei pelas escolas e objetivam assegurar que a implementação ocorrerá. A ideia de progressão expressa no advérbio "gradativamente", empregado no artigo $1^{\circ}$, deu margem às diversas interpretaçôes sobre o modo como a disciplina Língua Espanhola deveria ser inserida nos currículos plenos do ensino médio (EM), ou seja, em todas as séries até 2010. A textualização da passagem "gradativamente, nos currículos plenos do ensino médio", do artigo $1^{\circ}$, associada ao "processo 
de implantação deverá estar concluído no prazo de cinco anos, a partir da implantação desta Lei”, expressos na Lei no 11.161/2005, em alguns contextos do âmbito escolar, foi entendida como oferta da disciplina em uma série apenas do EM e a implantação em alguns casos foi a partir do ano de 2010, prazo final para que a lei fosse colocada em prática.

No exercício da docência e da pesquisa, depreendi da observação da realidade escolar, expressa nos dizeres dos sujeitos-professores de E/LE da escola básica e do corpus coletado, que a execução da lei se desdobrou em interpretaçóes com os mais diversos (des)interesses, pois há pontos de subjetivação ao longo de toda a textualidade (Orlandi, 2007). Assim sendo,

A dificuldade da implementação da Lei no 11.161/2005 e algumas das mobilizaçóes geradas por seus efeitos de sentido podem referir-se à negaçáo da latinidade, da identidade latino-americana, que imaginariamente podem não ser constitutivas das representaçóes identitárias do povo brasileiro (Carvalho, 2017, 551)

Destacamos que as representaçóes da globalização, em especial a dimensão da homogeneização cultural com a equação: globalização = ocidentalização = norte-americanização = mecdonaldização (Kumaravadivelu, 2006), que recorrentemente atravessa o imaginário brasileiro, precisa ser ressignificada nas políticas de educação linguística. A negação da nossa identidade latinoamericana, as resistências às políticas de fomento da língua espanhola nos impedem de vislumbrar um universo idiomático dos mais amplos e com maior capacidade de consumo cultural no mundo, com mais de 500 milhóes de hispanófonos, como destaca Canclini (2003). 
Dando sequência à minha trajetória acadêmico-profissional e relacionando-a às condiçôes de produção do arquivo jurídico, analisaremos os efeitos de sentido da seguinte resolução para as escolas do estado de Minas Gerais.

\section{1.Exercício prévio de desmonte da lei do espanhol: Resolução SEE-MG $n^{\circ} 2.742$ (2015)}

Como vimos, o acontecimento singular da lei do espanhol (2005), que definiu qual idioma deveria ser obrigatoriamente ofertado no ensino médio, mobilizou relaçóes de poder inerentes ao espaço escolar, na medida em que promoveu a desestabilização de poderes linguísticos já "cristalizados”, incitou um rearranjo da gramática escolar, demandou uma reflexão mais ampla sobre a política linguística e a democratização dos saberes escolares, dentre outros aspectos.

Indubitavelmente, os efeitos dessas mobilizações ocorridas nas esferas políticas e educacionais, geraram documentos que apresentam estratégias discursivas promotoras da intenção de apagamento das práticas viabilizadas pela lei do espanhol, acontecimento que possibilitou o contato e o confronto com outra opção de oferta de LE nas escolas de Educação Básica, como aponta a pesquisa de Carvalho (2015). Um exemplo de documento é a Resolução no 2.742, de 22 de janeiro de 2015, da Secretaria de Educaçáo de Minas Gerais, que expressa mais uma deriva de sentido da Lei no 11.161/2005. Em sua textualidade a RESOLUÇÃO SEE No 2.742, DE 22 DE JANEIRO DE 2015, dispóe sobre o ensino médio nas escolas da rede pública estadual de 
MG e "RESOLVE: Art. 1 O ensino médio, etapa conclusiva da Educação Básica, terá duração de 3 (três) anos, com carga horária anual de 833 horas e 20 minutos, totalizando 2.500 horas. Art. 2o A estrutura curricular do ensino médio será conforme o ANEXO desta Resolução [...]” (Minas Gerais, 2015, S.N,).

Tal resolução se inicia apresentando sobre qual temática legisla e salienta que a decisão da secretária, que assina o texto, apresentando um efeito de autoria, está amparada pela então vigente LDB 9.394 (1996). Mais adiante, o texto da lei apresenta um quadro-tabela com os conteúdos básicos comuns para o Ensino Médio. $\mathrm{Na}$ área de linguagens consta apenas o sintagma língua estrangeira, e na coluna ao lado, dois módulos-aula semanais.

$\mathrm{O}$ que língua estrangeira silencia? O que esse sintagma não deixa dizer? Em princípio, na textualidade, temos um silenciamento com a não definição e a não nomeação de qual é a língua estrangeira mencionada. Portanto, permite-se a pressuposição de que esta pode ser qualquer LE que tenha sido escolhida pela comunidade, conforme prevê a LDB 9.394, já que "ao longo do dizer, há toda uma margem de não-ditos que também significam” (Orlandi, 2007, 82).

O subentendido do enunciado língua estrangeira está na memória discursiva referente ao arquivo jurídico da política linguística e, na materialidade da Resolução é (re)velado na recomendação (1), que no fio do dizer das Recomendaçóes para a elaboração do quadro curricular, informa que:

(1) A segunda língua estrangeira será ofertada em cumprimento à Lei Federal $n^{0} 11.161 / 05$, sendo a oferta obrigatória pela escola e a matrícula 
facultativa pelo aluno. Ocorrendo a opção pela segunda língua estrangeira moderna, esta deverá ser ofertada em contra turno. (Minas Gerais, 2015, 9 , grifos nossos)

Em nosso gesto interpretativo, a artimanha discursiva de recomendação (1) aponta para uma imposição que fere o artigo $2^{\circ}$ da extinta Lei do espanhol, em vigência em 2015. Assim, ao empregar o sintagma em cumprimento para conferir credibilidade à legislação, realizando uma determinação previamente estabelecida na lei do espanhol, a SEE estaria isenta de quaisquer reponsabilidades legais. Entretanto, esta constitui-se numa estratégia discursiva de desvio da atenção dos leitores para a posterior nomeação da língua espanhola como segunda, adjetivo que expressa algo de qualidade inferior, secundário e, num sentido figurado, exprime rivalidade. Assim sendo, o enunciado contra turno filia-se a esses sentidos, ratificando e reverberando no discurso dessa resolução a tentativa de fracionamento, apagamento, invisibilidade e consequente desoficialização do ensino de E/ LE nas escolas da rede estadual de Minas Gerais.

Depreendemos que os sentidos estão determinados ideologicamente na memória discursiva das mencionadas legislaçôes, seja na ideologia de uma integração regional latino-americana seja na ideologia de que a "globalidade da língua e a conectividade da economia mundial garantirão que o inglês continue a reinar de modo supremo” (Kumaravadivelu, 2006, 145). Assim, essa ideologia "não está na essência das palavras, mas na discursividade, isto é, na maneira como no discurso, a ideologia produz seus efeitos, materializando-se nele" (Orlandi, 2007, 43). Destacamos que os processos 
ideológicos mencionados deveriam convergir para sermos capazes de elaborar políticas públicas para uma educação linguística plurilíngue e multicultural.

\section{2. Hierarquização e revogação: a super lei 13.415/2017 melhora ou piora a oferta de línguas estrangeiras?}

Em meu percurso de doutoramento fui surpreendida com a Reforma do Ensino Médio $^{10}$, instituída pela medida provisória no 746 e transformada na Lei 13.415/2017. Essa legislação altera a Lei de Diretrizes e Bases da Educação Nacional (LDB), institui a Língua Inglesa como obrigatória e a Língua Espanhola como preferencial para ser ofertada na parte diversificada. Inegavelmente estamos, novamente, diante de um projeto de governo, e náo de Estado, inserido em uma globalização imaginada como interação, mas que se configura como um processo segmentado e desigual, que intensifica a dependência recíproca entre as sociedades centrais e as elites das periferias (Canclini, 2003).

As globalizaçóes, "como conjuntos de relaçóes sociais que se traduzem na intensificação das interações transnacionais, sejam elas práticas interestatais, práticas capitalistas globais ou práticas sociais e culturais transnacionais" (Souza Santos, 2011, 85), longe de serem consensuais, são um vasto campo de conflitos. Esses complexos processos de transformações incluem as políticas educacionais, conforme observamos em reformas educacionais brasileiras,

10 Informaçôes oficiais sobre o novo Ensino Médio, disponível em: <http://portal.mec.gov.br/ component/content/article?id=40361\#nem_01>. Acesso em 04/07/2018. 
como a super lei 13.415/2017, dirigida "para a formação profissional mais do que para a construção de cidadania” (Souza Santos, 2011, 38). Esse ato normativo instaura a Base Nacional Comum Curricular ${ }^{11}$ (BNCC) que define "aprendizagens" ao longo da Educação Básica. Em suma, a super lei reverbera severos desdobramentos da política de ajustamento estrutural imposta pela globalização que, na lógica do capitalismo neoliberal, tem de servir aos interesses do mercado. Por certo, toda essa configuração atravessará os sujeitos professores e estudantes possibilitando a emergência de identidades e subjetividades.

A vigente legislação, nos artigos apresentados a seguir:

$\$ 5^{\circ}$ No currículo do ensino fundamental, a partir do sexto ano, será ofertada a língua inglesa.

$\$ 4^{\circ}$ Os currículos do ensino médio incluirão, obrigatoriamente, o estudo da língua inglesa e poderão ofertar outras línguas estrangeiras, em caráter optativo, preferencialmente o espanhol, de acordo com a disponibilidade de oferta, locais e horários definidos pelos sistemas de ensino.(Brasil, 2017, s.n., grifos nossos)

Diferentemente das legislações do arquivo jurídico anteriormente apresentadas neste artigo, a Lei 13.415/2017 nomeia e hierarquiza as línguas estrangeiras, pressupondo que uma língua tem mais valor que a outra. As

11 "A Base Nacional Comum Curricular (BNCC) é um documento de caráter normativo que define o conjunto orgânico e progressivo de aprendizagens essenciais que todos os alunos devem desenvolver ao longo das etapas e modalidades da Educação Básica, de modo a que tenham assegurados seus direitos de aprendizagem e desenvolvimento, em conformidade com o que preceitua o Plano Nacional de Educação (PNE). Este documento normativo aplica-se exclusivamente à educação escolar [...]". Disponível em: <http://basenacionalcomum.mec.gov.br/>. Acesso em 15/02/2019. 
formas e efeitos dessa nominalização emergem no/do discurso neoliberal que, através das operaçôes de nominalização "naturaliza as tomadas de posições neoliberais, espalhando-as como meras evidências e expressão inatingível da realidade" (Dahlet, 2015, 206).

Em nossa perspectiva discursiva, a palavra trará sempre a marca de um outro discurso, de outras vozes, também de suas censuras e silenciamentos (Authier-Revuz, 1990), como mostram as marcas enunciativas será ofertada (artigo $5^{\circ}$ ) e poderão ofertar (artigo 4\%). Tais marcas asseveram a hierarquização e relação de subalternização entre a língua inglesa e as demais línguas estrangeiras. O sintagma será ofertada, empregado na voz passiva, exprime efeito de garantia da oferta da língua inglesa (LI) no ensino fundamental, e não há margem para o ensino-aprendizado de outra LE. Ou seja, há um provimento de total hegemonia à LI no território nacional no segmento fundamental e um completo apagamento da possibilidade de um ensino plurilíngue e multicultural. No artigo $4^{\circ}$, o emprego do sintagma "poderão ofertar", coloca as línguas estrangeiras à margem da LI, que está determinada (obrigatoriamente) no currículo do ensino médio. Assim, resta às LEs um futuro de incertezas, de poucas possibilidades no cenário educacional brasileiro, logo de subalternidade na produção do conhecimento.

Além disso, os condicionantes optativo, disponibilidade de oferta, locais e horários, conforme pesquisas recentes (Amaral; Almeida, 2010; Carvalho, 2015; Barros; Costa, 2010; Rodrigues, 2012; Reis, 2017), filiam-se ao sistema de enunciabilidade da (in)viabilidade do ensino-aprendizado do espanhol. Em outras palavras, as medidas propostas na super lei 13.415/2017, dentre 
elas, o artigo 22, "Art. 22. Fica revogada a Lei no 11.161, de 5 de agosto de 2005” (Brasil, 2017, n. p.), acarretam a reduçáo de disciplinas da formação básica, pois impactam as poucas instituições que já ofertam outras LEs, especialmente o espanhol.

A Lei 13.415/2017 é um dispositivo de poder arbitrário, imposto à comunidade acadêmica escolar sem amplo debate e discussão pela sociedade ou especialistas. Seu caráter ideológico e político, dotado de intencionalidades específicas, tem efeitos da globalização que agrava assimetrias e desigualdades na América (Canclini, 2001), e desse modo, permite que a escola brasileira, numa dimensão macrossocial, repercuta a violência simbólica, reproduza e legitime desigualdades sociais (Bourdieu, 1979).

\section{COMO REPERCUtiU A LEI DO ESPANHOL?}

Nesta seçáo lançamos luz sobre a voz de professores acerca da implantaçáo da Lei do espanhol e seus impactos em escolas de Minas Gerais. Entendermos que, muitos dos efeitos de sentido depreendidos na pesquisa de Carvalho (2015), aqui retomada, dizem respeito às implicaçôes na constituição identitária profissional e na subjetividade do sujeito-professor. Esse é constituído por discursos, em constante produção, conforme o lugar sócio-histórico que ocupa. Desse modo, o atravessamento pelos discursos legais que normatizam o ensino de LEs sempre estará presente nas enunciaçôes dos docentes.

Em nossa abordagem teórico-metodológica, teoria do discurso atravessada pela psicanálise, concebemos o sujeito-professor como sujeito efeito de 
linguagem (Pêcheux, (2008), que foi falado antes de falar, que traz marcas do discurso do Outro, o que implica considerar que o sujeito não é a origem do dizer nem controla tudo o que diz.

\subsection{Operação de tapa-buraco com quebra-galho: o professor que se vire!}

A partir de uma entrevista semiestruturada em que foram convidados a discorrerem sobre os impactos da Lei 11.161 na prática profissional, os sujeitos-professores enunciam os dizeres, apresentados através dos recortes discursivos (RDs):

RD 01

[...] Aí ela pega uma sala em que o aluno não sabe nada, absolutamente, não teve uma base, o professor que deixou náo era professor de espanhol, era professor de matemática, (risos) que estava suprindo, dando aula de espanhol pra cumprir a lei, a oferta da lei [...]. (Professora Sandra)

Na representaçáo da professora Sandra, materializada no RD 01, o gesto de aceitar que professores não qualificados lecionem a Língua Espanhola implica em não ensinar nada. Depreendemos que o sujeito-professor se coloca no lugar do profissional qualificado ao criticar os demais, não era professor de espanhol, era professor de matemática, (risos) e o riso aparece como uma marca enunciativa, que pode ser entendida como uma expressáo de incredulidade e ironia com relação aos desdobramentos da Lei na prática escolar. Esse dizer encontra eco em outro RD, no qual outro docente, após posicionar-se contra a legislação, também enuncia, Além do mais, você está publicando uma lei 
sem ter um corpo docente para dar essas aulas, reverberando a mesma posição de marcar a carência de professores licenciados para lecionar a disciplina. A professora Cristiana (C) se refere aos impactos da seguinte forma:

RD 02

C: Eu acho que tá tudo assim, muito IMPROVISADO, tudo muito improvisado e imediatista. Tem que ter espanhol, entáo a gente tem que colocar professor de espanhol lá. [...] eles não estão preocupados com o rendimento, por assim dizer, com essa progreSSÃO, néh? dos alunos...ou coisa parecida, eles estão preocupados mesmo por tapar buraco.

P: E melhoria?

C: Melhoria...acho que está por vir [...]andaram comprando alguns materiais. [...] hoje em dia não, é bem assim, como se diz, quebra galho mesmo, o sonzinho é muito ruim, [...] e vários outros probleminhas que assim, dificultam nossa prática, néh?

(Professora Cristiana)

Através do uso enfatizado e repetitivo do verbo improvisar, a docente ressalta seu ponto de vista com relação à implementação do E/LE em sua realidade escolar. Uma analogia entre uma operação de tapar buraco é usada para se comparar com a situação da disciplina na escola. Essa expressão, em seu uso coloquial, refere-se a um trabalho mal feito, sem cuidado e sem capricho. Em tom de queixa, sua posição é a de questionar os gestores escolares e as políticas públicas com relação ao desinteresse pelo desempenho acadêmico dos estudantes e, novamente, é feita uma menção ao descuido com a capacitação de professores de E/LE, expresso em colocar professor de espanhol lá. Ao empregar o dêitico lá e as marcas linguísticas eles não estão preocupados e eles 
estão preocupados mesmo por tapar buraco, o sujeito marca a heterogeneidade discursiva ao trazer outra voz, o discurso do outro, objetivando mostrar o seu afastamento desses dizeres. Ou seja, na representação do sujeito-professor, o que importa para o discurso político-pedagógico é constar que há o professor lecionando a disciplina, conforme mostram os RDs anteriores, independente da qualificação e do projeto de ensino da escola. Assim, na passagem e vários outros probleminhas que assim, dificultam nossa prática, néb?, o professor assume uma posição de quem também precisa improvisar, ou seja, o professor não qualificado tapa-buraco e o qualificado também.

Ressoando os efeitos de sentido acerca do impacto da Lei do espanhol do RD02, temos o modo de narrar do Professor Leandro:

RD 03

Eu não percebo o impacto [...] como é algo obrigatório, você faz como eu tinha dito anteriormente, você oferta sem projeto NENHUM, sem ter biblioteca na escola com UM dicionário da língua, você náo tem material NENHUM, você náo tem suporte NENHUM// ahh/ e fica apenas sendo uma matéria a mais [...].

(Professor Leandro)

A argumentação é marcada pelo uso repetido cinco vezes do pronome você, que, em um deslize inconsciente, aponta para a opacidade da linguagem, referindo-se às instituiçóes escola e governo (Lei), e não ao interlocutor pesquisador. Desse modo, um efeito de sentido possível diz da indignação do sujeito com a imposição de uma Lei em uma infraestrutura de quebragalho. O significante nenhum, empregado reiteradamente de forma enfática, 
associado ao uso da preposição sem, indica ausência total, nulidade, falta de preparo e planejamento do espaço e da gestão escolar, remetendo à operação de tapar buraco, enunciada no RD 02, permitindo o efeito de sentido de insatisfação e descrédito em relação à Lei.

Os dizeres reverberam a memória discursiva em um processo de desoficialização das disciplinas de línguas estrangeiras (Rodrigues, 2012), que ocorreu na história da sua implementação pelas instâncias governamentais, o que apaga ou silencia quais LEs devem ser ensinadas, criando insegurança e descrédito entre profissionais envolvidos. No RD 03, a desoficialização do E/LE também está expressa na condição precária em que ocorre a implementação da Lei 11.161. E agora que a super lei define a LE a ser estudada, estão na sua textualidade propostas de investimento que minimizem os impactos mencionados pelos professores? Há infraestrutura nas escolas de Educação Básica e professores de Língua Inglesa capacitados para a docência nesses espaços? Terão os "sistemas de ensino" a devida "disponibilidade de oferta, locais e horários" para que atuem os professores de outras LEs, "preferencialmente o espanhol"?

\subsection{Espanhol e/ou inglês? Afinal, qual língua estrangeira se aprende na escola?}

No fio do dizer do RD 04, o professor enuncia sobre os desdobramentos da Lei 11.161:

RD 04

O que eu percebo / a melhoria que a gente deu, e foi sim uma melhoria, foi proporcionar para os alunos que já estudaram oito anos o inglês e náo verem resultados nenhum, nestes oito anos de estudo, propiciar outra aprendizagem, 
néh? Outra opçáo, a melhoria no caso, foi para os alunos que não querem mais aprender inglês, porque não acreditam que vão aprender. (Professor Leandro)

Através da repetição do significante melhoria, o sujeito-professor atribui o impacto positivo da Lei à possibilidade de oferta de mais uma LE para os estudantes. Assim, nas passagens não verem resultado nenhum, vestígios de tensão entre as línguas inglesa e espanhola podem ser observados, bem como na heterogeneidade marcada nos significantes outra aprendizagem, outra opção, com a reiteração do pronome adjetivo outra, indicando a existência de uma possível demanda por parte dos estudantes de uma LE distinta, diferente, já que, conforme as imagens expressas no discurso do professor, eles não querem mais aprender inglês porque não acreditam que avançarão nesse estudo.

Nesses recortes, a Lei 11.161 é representada como mecanismo de poder que promove, como benefício, mais uma oferta de LE que, em igualdade com a Língua Inglesa, ainda em uma operação de tapa-buraco, disponibiliza uma alternativa de aprendizagem para estudantes que não querem, não conseguem ou não se identificam com as discursividades da LI. No imaginário dos sujeitos-professores esta é uma representação de melhoria proporcionada pela legislação, embora gere tensão e disputa pelo poder no espaço escolar, em função de equívocos na interpretação da Lei.

\section{IN(CONCLUSÖES)}

No atual contexto de políticas públicas brasileiras que vislumbram reformar, ou seja, reconstruir o antigo sem discutir com a sociedade o que 
seriam o novo e seus desdobramentos, assistimos a manobras discursivas que visam retrocessos, perdas de direitos e o engodo no sistema educacional, na assistência e na previdência social. Entendendo que as condiçóes políticas exercem um papel central na constituição do sujeito, nos domínios de saber e nas relaçóes com a verdade, como afirma Foucault (1973), problematizamos e inquirimos o sistema de enunciabilidade da (in)viabilidade do ensinoaprendizado do espanhol. Nesse sentido, os dispositivos de poder apresentados repercutem efeitos de sentido da Lei das Metades (Foucault, 1973), por serem incompletos, arbitrários e/ou equivocados em seus enunciados acerca da oferta de LE nas escolas de Educação Básica.

Em contraste, é na dimensão do sistema de enunciabilidade da possibilidade, constituído pelos acontecimentos dos estados de Sergipe, Paraíba, Rondônia, Rio Grande do Sul e São Paulo, com suas legislaçôes que viabilizam a continuidade do ensino-aprendizado de espanhol, articulada à representação do benefício da Lei 11.161, depreendida nos dizeres dos professores (RD 04/05), que nos identificamos e projetamos a democratização de oportunidades de aprendizado, o desenvolvimento de políticas públicas para uma educação linguística plurilíngue e multicultural, bem como desejamos uma formação cidadã e humanizada que extrapole as demandas do mercado de trabalho.

\section{REFERÊNCIAS BibLIOGRÁFICAS}

Amaral, Eduardo Roque Tadeu; Almeida, Elizabeth Guzzo de. "Qual é o lugar do espanhol nas escolas de ensino médio de Minas Gerais?” In: CONGRESSO INTERNACIONAL DE PROFESSORES DE LÍNGUAS OFICIAIS DO 
MERCOSUL, 1., 2010, Foz do Iguaçu. Anais do I CIPLOM. Foz do Iguaçu, 2010. 313-323.

Authier-Revuz, Jaqueline. "Heterogeneidade(s) enunciativa(s)". In: Cadernos de Estudos Linguísticos, Campinas, n. 19, jul./dez., 25-42, 1990. Disponível em: http://revistas.iel.unicamp.br/index.php/cel/article/view/3012/4095. Acesso em: 02 fev. 2014.

Barros, Cristiano Silva de; Costa, Elzimar Goettenauer de Marins. Espanhol: ensino médio. Brasília: Ministério da Educação/Secretaria de Educação Básica, 2010.

Bertoldo, Ernesto Sérgio. "Ensinar e aprender língua estrangeira: desafios pela problemática da subjetividade”. In: Cavallari, J. S.; Uyeno, E. Y. (Orgs.). Bilinguismos: subjetivação e identificaçóes nas/pelas línguas maternas e estrangeiras. Campinas: Pontes Editores, 2011, 337-343.

Bourdieu, Pierre. "Les trois états du capital culturel ". In: Actes de la recherche en sciences sociales, Paris, n. 30, nov. 3-6, 1979. Disponível em: <https://www.persee. fr/doc/arss_0335-5322_1979_num_30_1_2654>. Acesso em 05 jul. 072018.

Brasil (a). Lei No 11.161, de 05 de agosto de 2005. Dispóe sobre o ensino da língua espanhola. Palácio do Planalto, Brasília, DF, 05 ago. 2005. Disponível em: $<$ http://www.planalto.gov.br/ccivil_03/_Ato2004-2006/2005/Lei/L11161. htm>. Acesso em: 28 mar. 2019.

Brasil (b). Lei 13.415/2017. Disponível em: <http://www.planalto.gov.br/ccivil_03/_ Ato20152018/2017/Lei/L13415.htm\#art22>. Acesso em 27 mar. 2019.

Brasil (c). LDB 9697. Disponível em: <http://portal.mec.gov.br/seesp/arquivos/ pdf/lei9394_ldbn1.pdf>. Acesso em: 29 mar. 2019.

Canclini, Néstor García. A globalização imaginada. Trad. Sérgio Molina. 2. ed. São Paulo: Iluminuras, 2003.

Carvalho, Fernanda Peçanha. Representaçóes dos professores de espanhol a respeito da lei federal no 11.161 e do ensino da língua após sua promulgação. 2015. 185 
f. Dissertação (Mestrado em Linguística Aplicada) - Faculdade de Letras, Universidade Federal de Minas Gerais, Belo Horizonte, 2015.

Dahlet, Patrick. "(Re)produzir o inquestionável: nominalização, generalização e naturalização no discurso neoliberal”. In: EID $\mho A$ - Revista Eletrônica de Estudos Integrados em Discurso e Argumentação, Ilhéus, n. 8, 206-221, jun. 2015.

Eckert-Hoff, Beatriz Maria. O dizer da prática na formação do professor. Chapecó: Argos, 2002.

Foucault, Michel. A arqueologia do saber. 8. ed. Rio de Janeiro: Forense Universitária. 2013.

Foucault, Michel. (1973). A verdade e as formas jurídicas. Tradução de Roberto Cabral de Melo Machado e Eduardo Jardim Moraes. $3^{\text {a }}$ ed. Rio de Janeiro: NAU Editora, 2003. 158 p. Título original: La vérité et les formes juridiques.

Kumaravadivelu, Bala. "A Linguística Aplicada na era da globalização". In: Moita Lopes, L. P. (Org.). Por uma Linguistica Aplicada Indisciplinar. Sáo Paulo: Parábola, 2006.

MINAS GERAIS (a). RESOLUÇÃO SEE No 2.742, DE 22 DE JANEIRO DE 2015. Disponível em: <http://www2.educacao.mg.gov.br/images/documentos/274215-r.pdf $>$. Acesso em: 29 mar. 2019.

Minas Gerais (b). Resolução No 2.742/2015. In: Diário do Executivo, 23/01/2015. p. 9 Disponível em: http://jornal.iof.mg.gov.br/xmlui/handle/123456789/137325. Acesso em: 29 mar. 2019.

Orlandi, Eni de Lourdes Puccinelli. Análise de discurso: princípios e procedimentos. 6. ed. Campinas: Pontes, 2007.

Pêcheux, Michel. A análise do discurso: três épocas. In: GADET, F.; HAK, T. (Orgs.). Por uma análise automática do discurso: uma introduçáo à obra de Michel Pêcheux. Campinas: Ed. Unicamp, 2010. 307-315.

Pêcheux, Michel. $O$ discurso: estrutura ou acontecimento. Tradução de Eni P. 
Orlandi. 5. ed. Campinas: Pontes, 2008.

Reis, Isabel Martins. O lugar da língua espanhola em escolas de ensino técnico: um olhar crítico sobre a implantação da disciplina em Minas Gerais. Dissertação. 149f. (Mestrado em Estudos Linguísticos) - Faculdade de Letras, Universidade Federal de Minas Gerais, Belo Horizonte, 2017.

Rodrigues, Fernanda Castelano. Lingua viva, letra morta: obrigatoriedade e ensino de espanhol no arquivo jurídico e legislativo brasileiro. São Paulo: Humanitas, 2012.

Santos, Boaventura de Souza (Org). A globalização e as ciências sociais. São Paulo: Cortez, 2011. 